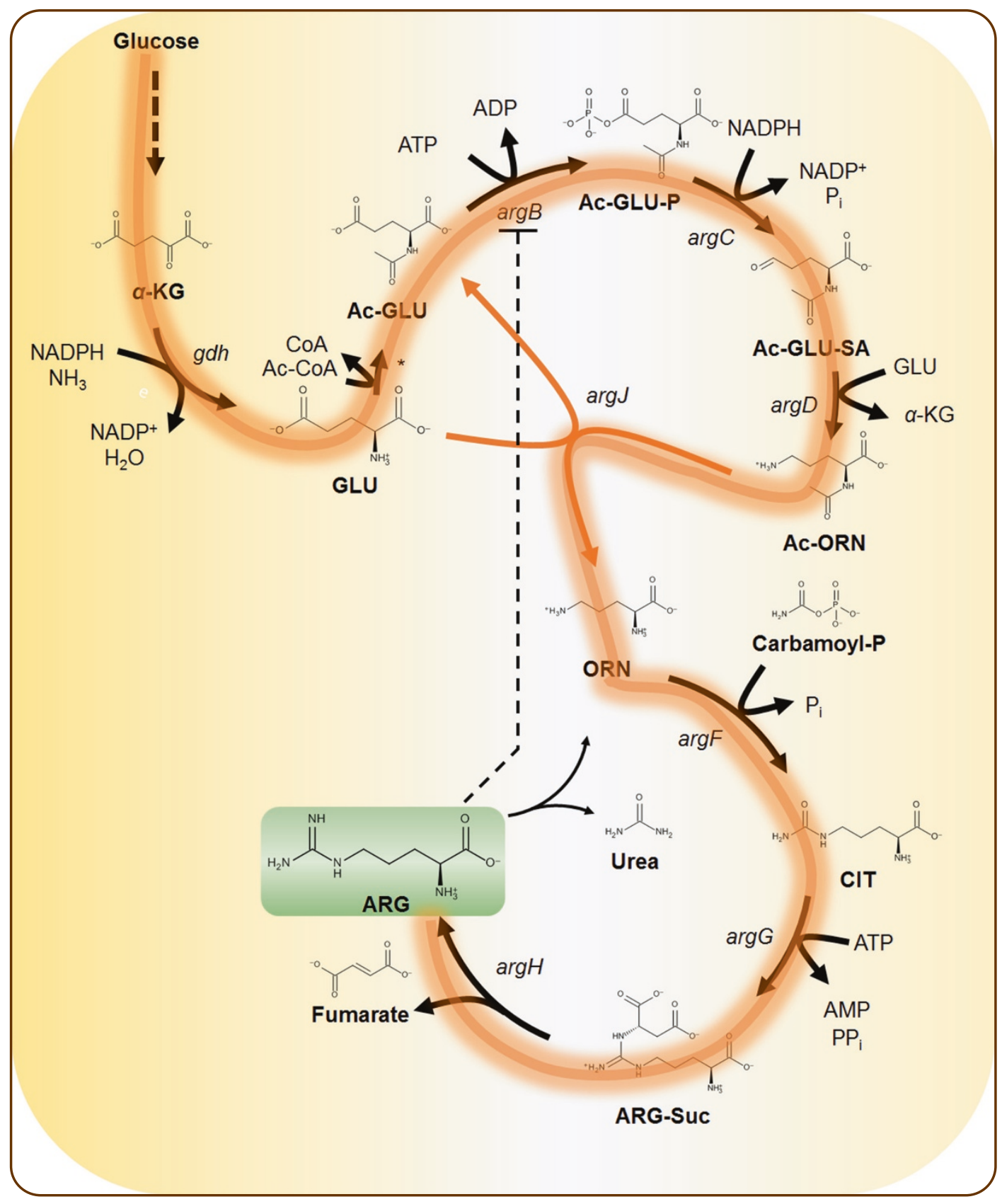

\title{
Metabolic engineering of microorganisms for the production of $L$-arginine and its derivatives
}

Shin and Lee 


\title{
Metabolic engineering of microorganisms for the production of $\mathrm{L}$-arginine and its derivatives
}

\author{
Jae Ho Shin ${ }^{1}$ and Sang Yup Lee ${ }^{1,2,3^{*}}$
}

\begin{abstract}
L-arginine (ARG) is an important amino acid for both medicinal and industrial applications. For almost six decades, the research has been going on for its improved industrial level production using different microorganisms. While the initial approaches involved random mutagenesis for increased tolerance to ARG and consequently higher ARG titer, it is laborious and often leads to unwanted phenotypes, such as retarded growth. Discovery of L-glutamate (GLU) overproducing strains and using them as base strains for ARG production led to improved ARG production titer. Continued effort to unveil molecular mechanisms led to the accumulation of detailed knowledge on amino acid metabolism, which has contributed to better understanding of ARG biosynthesis and its regulation. Moreover, systems metabolic engineering now enables scientists and engineers to efficiently construct genetically defined microorganisms for ARG overproduction in a more rational and system-wide manner. Despite such effort, ARG biosynthesis is still not fully understood and many of the genes in the pathway are mislabeled. Here, we review the major metabolic pathways and its regulation involved in ARG biosynthesis in different prokaryotes including recent discoveries. Also, various strategies for metabolic engineering of bacteria for the overproduction of ARG are described. Furthermore, metabolic engineering approaches for producing ARG derivatives such as L-ornithine $(\mathrm{ORN})$, putrescine and cyanophycin are described. ORN is used in medical applications, while putrescine can be used as a bio-based precursor for the synthesis of nylon-4,6 and nylon-4,10. Cyanophycin is also an important compound for the production of polyaspartate, another important bio-based polymer. Strategies outlined here will serve as a general guideline for rationally designing of cell-factories for overproduction of ARG and related compounds that are industrially valuable.
\end{abstract}

Keywords: Metabolic engineering, L-Arginine, L-Ornithine, Putrescine, Biopolymers, Polyaspartate

\section{Introduction}

L-arginine (ARG) is a semi-essential amino acid that is important for medicinal and industrial applications. ARG is known to stimulate secretion of growth hormones [1], prolactin [2], insulin [3] and glucagon [4], promote muscle mass [5], enhance wound healing [6] and as a precursor for nitric oxide [7]. Physiological importance of ARG supplementation is further raised by the important roles of nitric oxide in cardiovascular and neurological systems [8]. For many important applications of ARG, its industrial

\footnotetext{
* Correspondence: leesy@kaist.ac.kr

${ }^{1}$ Metabolic and Biomolecular Engineering National Research Laboratory, Department of Chemical and Biomolecular Engineering (BK21 Plus Program), Center for Systems and Synthetic Biotechnology, Institute for the BioCentury, KAIST, 291 Daehak-ro, Yuseong-gu, Daejeon 305-701, Republic of Korea ${ }^{2}$ BioProcess Engineering Research Center, KAIST, Daejeon 305-701, Republic of Korea

Full list of author information is available at the end of the article
}

level production has become an important task. It can be produced by microbial fermentation at an industrial scale [9] as for other amino acids such as L-glutamate (GLU) [10], L-lysine (LYS) [11], L-tryptophan (TRP) [12], Lvaline (VAL) [13], L-threonine (THR) [14] and L-alanine (ALA) [15]. For these amino acids, model organisms such as Corynebacterium glutamicum [16] and Escherichia coli [17] have been widely used as production hosts, while ARG production has been performed using B. subtilis [18] and C. glutamicum [9]. It has been almost six decades since ARG production has been explored and studied using microorganisms. As in the cases for other amino acid production, random mutagenesis has been used in order to obtain efficient producer strains [19]. However, random mutagenesis is problematic due to the unwanted genomic changes introduced. Thus, much effort has been exerted to develop strains through metabolic engineering. 
Systems metabolic engineering now allows construction of efficiently performing cell-factories for the microbial production of not only amino acids but also bio-fuels [20,21], pharmaceuticals [22], bio-plastics [23], platform chemicals [24-26] and even silk proteins [27]. It is powered by rapidly advancing tools and continuously accumulating genetic and molecular information. It also aims to develop strains based on optimization of the entire bioprocess from strain design to industrial level cultivation. Its strategies include deletion of competing pathways [28], strengthening upstream pathways for increasing precursor pool [11], engineering transporters [29] and fine-tuning expression levels [30]. Systems metabolic engineering approach has been successfully applied in order to rationally design ARG producer strain for the efficient industrial level production which can be potentially engineered to produce ARG derivatives as well [9].

Systems metabolic engineering strategies can also be used for producing ARG-related compounds, such as Lornithine (ORN), putrescine, and cyanophycin that share common pathways. ORN is a non-proteinogenic amino acid that has shown to improve athletic performance along with ARG and L-citrulline (CIT), another intermediate metabolite in the ARG biosynthetic pathway [31]. Putrescine is a four-carbon diamine platform chemical that can be incorporated into various polymers such as nylon-4,6 and nylon-4,10. Cyanophycin can be used to produce polyaspartate which is another bio-polymer for various technical applications. However, efficient metabolic engineering for such compounds has been limited by incomplete understanding on ARG biosynthesis even with the publically available genome sequences [32]. Here, we review the three major pathways for ARG biosynthesis in prokaryotes including the recent discoveries. We also discuss various strategies applied to engineer strains for the efficient production of ARG, ORN, putrescine and cyanophycin using recently established examples.

\section{L-Arginine biosynthetic pathway and its regulation}

In prokaryotes, there are three major biosynthetic pathways for ARG; "linear", "recycling" and the "new" pathways (Figure 1) [33,34]. Each pathway is comprised of eight enzymatic steps from GLU and the major differences in these pathways are in that different genes are involved for conversion of $N$-acetylornithine (Ac-ORN) for further downstream reactions toward ARG [35]. In the linear pathway (Figure 1A), Ac-ORN is converted to ORN by acetylornithinase (AOase; encoded by $\operatorname{argE}$ ) [36], whereas in the recycling pathway (Figure $1 \mathrm{~B}$ ) this is catalyzed by a different enzyme, ornithine acetyltransferase (OATase; encoded by argJ) [37]. In the third pathway, which has not been named, ORN is bypassed and instead $\mathrm{N}$-acetylcitrulline (Ac-CIT) is formed by acetylornithine carbamoyltransferase (AOTCase; encoded by
$\operatorname{argF}$, Figure 1C) [38]. While certain aspects of the pathway components are still under debate, they are undoubtedly important in ARG biosynthesis and metabolic engineering purposes.

In the linear pathway (Figure 1A), GLU is converted to acetylglutamate (Ac-GLU) by $N$-acetylglutamate synthase (NAGS, encoded by $\operatorname{argA}$ ) which is inhibited by ARG through negative feedback regulation [36,39]. Sequential catalytic reactions catalyzed by the next three enzymes, $N$-acetylglutamate kinase (NAGK, encoded by $\operatorname{argB}), N$-acetylglutamate semialdehyde dehydrogenase (encoded by $\operatorname{argC}$ ) and $N$-acetylornithine transaminase (encoded by $\arg D$ ), which are common in the three pathways (Figure 1), yield $N$-acetylornithine (Ac-ORN) [34]. The next step, which distinguishes the linear pathway from the other two pathways, is deacetylation of Ac-ORN by AOase to yield ORN [40,41]. The next and final steps are carried out by ornithine carbamoyltransferase (OTC or OTCase, encoded by $\operatorname{argF}$ ), argininosuccinate synthase (encoded by argG) and argininosuccinate lyase (encoded by $\operatorname{argH}$ ), which finally yield ARG [35]. This pathway has been found in a few species such as Myxococcus xanthus [41] and E. coli [36].

In many other prokaryotes including Geobacillus stearothermophilus (formerly Bacillus stearothermophilus) [37,42,43], Thermotoga neapolitana [42], Pseudomonads [44], Neisseria gonorrhoeae [45] Streptomyces coelicolor [46] and C. glutamicum (formerly Micrococcus glutamicus) [19,47], ARG is synthesized via the recycling pathway and many aspects remain unknown herein (Figure 1B). The recycling pathway is regarded as more evolved and economical than the linear pathway and is "recycling" in the sense that the acetyl group deacetylated from Ac-ORN in the fifth biosynthetic step (similarly as in AOase) is re-used to acetylate GLU in the first committed step (similarly as in NAGS) of the pathway (Figure 1B). The OATase involved in the recycling step is either monofunctional or bifunctional depending on the species. For example, the OATase from G. stearothermophilus [37] and N. gonorrhoeae [40] is bifunctional and accepts both Ac-CoA and Ac-ORN as substrates to acetylate GLU, whereas that from $S$. coelicolor only accepts Ac-ORN as a substrate and considered monofunctional [46]. However, many of monofunctional OATases are mislabeled as bifunctional and some are still being corrected [48]. For example, the OATase from C. glutamicum which had been known to be bifunctional for decades $[19,47,49-51]$ has been re-considered as monofunctional [52-54], while that from C. crenatum remains bifunctional [34]. For species such as S. coelicolor, the OATase is characterized. However, NAGS has not been identified in this bacterium, while new classes of NAGS are continuously being discovered for other species [53]. For example, the novel type of NAGS (C-NAGS) 

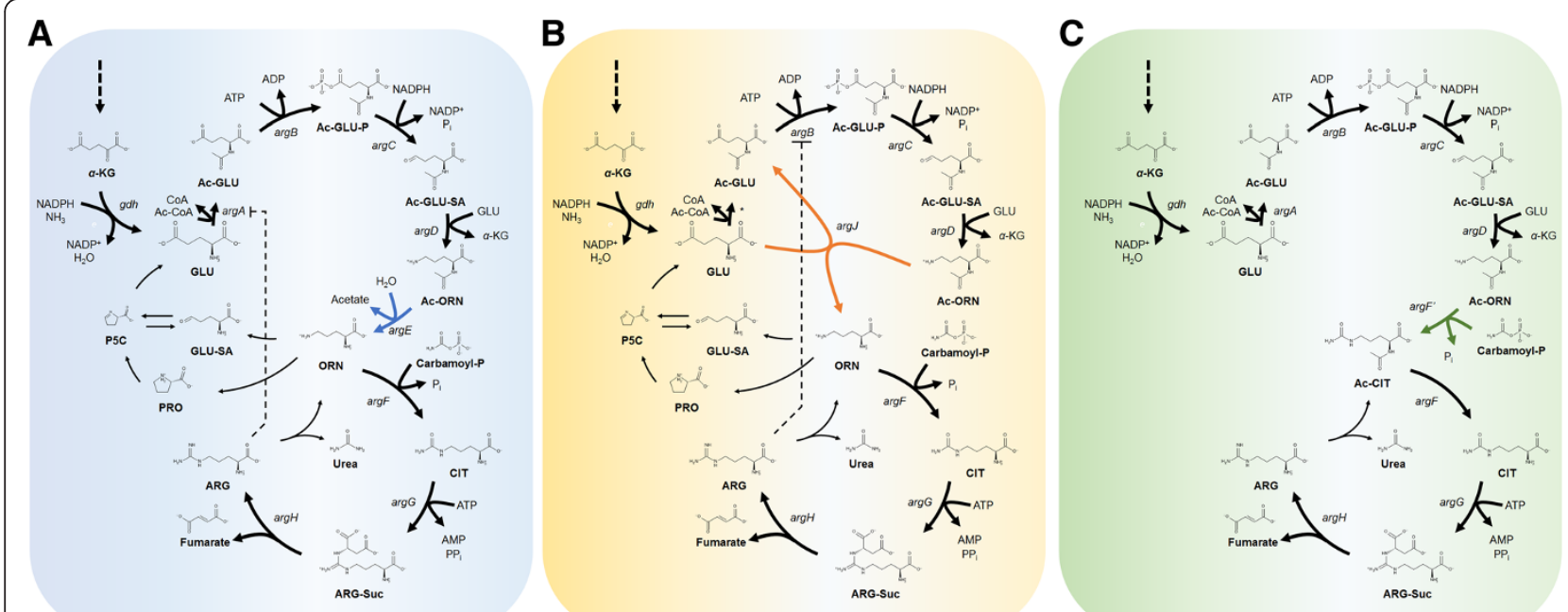

Figure 1 Representative ARG biosynthesis routes in prokaryotes. (A) The linear pathway, (B) the recycling pathway and (C) the newly discovered pathway for the ARG biosynthesis are shown. Dashed line indicates feedback inhibition by ARG on the first (NAGS) (A) and second (NAKG) (B) committed steps in the pathways. Blue arrows indicate argE used in the linear pathway (A). Orange arrows indicate argJ used in the recycling pathway (B). Green arrow indicates argF' used in the newly found pathway (C). ARG catabolic pathways are also shown. Ac-GLU,

N-acetylglutamate; Ac-GLU-P, N-acetylglutamyl-5-phosphate; Ac-GLU-SA, N-acetylglutmate-5-semialdehyde; ARG-Suc, L-argininosuccinate; GLU-SA, L-glutamate-5-semialdehyde; P5C, 1-pyrroline-5-carboxylate. The asterisk indicates putative NAGS that has not been characterized in

many organisms.

[53] encoded by cg3035 from C. glutamicum adds to the diversity of NAGS including (1) the classical NAGS (as in the linear pathway), (2) the bifunctional OATase (as in the recycling pathway), (3) $\operatorname{ArgH}(\mathrm{A})$ fusion types ( $\operatorname{argH}-\operatorname{argA}$ fusion) [55], and (4) the short versions of NAGS (SNAGS) [56]. Additionally, for species that have both NAGS and OATase such as G. stearothermophilus [43] and $N$. gonorrhoeae [57], there is a functional redundancy and the NAGS function is regarded as anaplerotic to replenish Ac-GLU [57,58]. Moreover, another distinctive feature of this pathway is that NAGK reaction instead of NAGS reaction is negatively regulated by ARG $[44,52,59,60]$.

In the newly discovered pathway (Figure 1C), AOTCase from Xanthomonas campestris transfers carbamoyl group from carbamoyl phosphate to Ac-ORN to form Ac-CIT [38]. Here, the formation of ORN is bypassed and ArgE deacetylates Ac-CIT to yield CIT. While the details of this pathway, as with the linear and recycling pathways, have not been fully explored, C. glutamicum and its related species with the recycling pathway are recognized as the organisms to most efficiently produce ARG.

In terms of the chromosomal genetic organization, ARG biosynthetic genes are diversely organized in different species, and that from C. glutamicum has been studied the most. In C. glutamicum, the $\operatorname{argCJBDFRGH}$ cluster is organized into two operons (argCJBDFR and $\arg G H)$ [52] and transcription of these operons are regulated by ARG [61], ArgR [62] and FarR [63], while the putative $\operatorname{argA}$ (cg3035, encoding C-NAGS) is separated from this cluster
[32,52,53]. FarR regulates transcription of the $\arg$ operon by binding to the upstream of $\arg C, \arg B, \arg F$ and $\arg G$ genes $[63,64]$. FarR additionally controls the ARG biosynthesis by binding to the upstream of the $g d h$ gene encoding glutamate dehydrogenase which converts $\alpha$ ketoglutarate $(\alpha-\mathrm{KG})$ into GLU [63]. Similarly, ArgR, a global regulator, binds to $\arg C$ and $\arg G$ promoters to control ARG biosynthesis [49] and the degree of downregulation is increased by ARG [61] but its binding affinity decreases by L-proline (PRO), which can be considered as a stimulator for ARG biosynthesis [65]. Additionally, other strains have different chromosomal organization in the ARG operon. For example, it is partially clustered in the order of $\operatorname{argCJBD}$ in the chromosome for gram-positive bacteria such as G. stearothermophilus and S. coelicolor $[46,66]$, while the bipolar organization of $\operatorname{argECBH}$ is found in gram-negative bacteria such as $E$. coli [67-70].

\section{Metabolic engineering for L-arginine production}

Initial approach to produce ARG at industrial scale began with random mutagenesis of microorganisms (Table 1). Mutants selected based on their resistance to antimetabolites and other analogues such as canavanine (CVN) [40,71], homoarginine [72], arginine hydroxamate (AHX) [18,73], 6-azauracil (6 AU) [74], 2-thiazolealanine (TA) [75], and sulfaguanine (SG) [75] have been used in early attempts to overproduce ARG. Mutations were induced by radiation [75,76] or treatment with mutagen such as $N$-methyl- $N$-nitro- $N$-nitrosoguanidine (NTG) $[18,75]$. The rational for this is to confer higher tolerance 
Table 1 ARG, ORN, putrescine and cyanophycin producing strains

\begin{tabular}{|c|c|c|c|c|c|}
\hline Product & Year & Strain (vector if any) & Remark & $\begin{array}{l}\text { Titer } \\
\text { (g/liter) }\end{array}$ & Reference \\
\hline \multirow[t]{20}{*}{ ARG } & 1971 & $\mathrm{AHr}-5$ & AHX resistant $B$. subtilis; test tube culture & 4.5 & {$[18]$} \\
\hline & \multirow[t]{5}{*}{1973} & AJ 3351 & B. ketoglutamicum ATCC 15587 mutant; SG ${ }^{R}$, & 2.1 & \multirow[t]{5}{*}{ [75] } \\
\hline & & AJ 3352 & A. paraffineus ATCC 19065 mutant; TA ${ }^{R}$, & 1.2 & \\
\hline & & AJ 3353 & M. ammoniaphilum ATCC 15354 mutant; TA ${ }^{R}$, & 2.9 & \\
\hline & & No. 348 & C. lilium NRRL B-2243 mutant; TA ${ }^{R}$ & 1.8 & \\
\hline & & No. 352 & B. flavum ATCC 14067 mutant; guanine auxotroph; TA & 34.8 & \\
\hline & 1977 & AAr-9 & B. subtilis OUT 8103 mutant; $6 A U^{R}$ & 28.0 & [74] \\
\hline & \multirow[t]{6}{*}{1981} & KY7690 & $\begin{array}{l}\text { B. subtilis ATCC } 15244 \text { mutant; AHX }{ }^{R}, 5 H \cup R^{R}, T^{R} A^{R}, 6 F^{R} P^{R}, 6 A U^{R}, 2 T U^{R} ; 5 \text { liter } \\
\text { bioreactor }\end{array}$ & 14.0 & \multirow[t]{6}{*}{ [73] } \\
\hline & & S. marcescens & IFO 3046 mutant; $A H X^{R}, N^{2} M^{R}$; test tube culture & 0.6 & \\
\hline & & M. ammoniaphilum & ATCC 15354 mutant; AHX ; test tube culture & 0.5 & \\
\hline & & M. sodonensis & ATCC 11880 mutant; AHX ; test tube culture & 4.0 & \\
\hline & & N. corynebacteroides & ATCC 14898 mutant; CVN ${ }^{R}$; test tube culture & 2.5 & \\
\hline & & N. rubra & NRRL 11094 mutant; $A H X^{R}$; test tube culture & 8.0 & \\
\hline & 2009 & RBid & C. glutamicum ATCC 13032, $\triangle \arg R$, A26V/M31V in ArgB; 5 liter bioreactor & 52.0 & [47] \\
\hline & 2009 & SYPA 5-5 & $\begin{array}{l}\text { C. crenatum mutant; optimization of two-stage oxygen supply strategy; } \\
5 \text { liter bioreactor }\end{array}$ & 36.6 & [76] \\
\hline & 2011 & $\begin{array}{l}\text { SYPA 5-5 (pJC-tac- } \\
\text { vgb) }\end{array}$ & C. crenatum mutant, vector-based overexpression of vgb from Vitreoscilla & 35.9 & [77] \\
\hline & 2011 & $\begin{array}{l}\text { SYPA 5-5 (pJCtac- } \\
\text { arg) }\end{array}$ & C. crenatum mutant, vector-based overexpression of argJ; 5 liter bioreactor & 42.4 & [34] \\
\hline & 2012 & SYPA-9039 (pJC-9039) & $\begin{array}{l}\text { C. crenatum SYPA5-5 harboring with vector-based overexpression of } \\
\text { argCJBDFRGH; } 5 \text { liter bioreactor }\end{array}$ & 45.3 & [78] \\
\hline & \multirow[t]{2}{*}{2014} & \multirow[t]{2}{*}{ AR6 } & $\begin{array}{l}\text { C. glutamicum ATCC 21831; AHX }{ }^{R}, C V N^{R} \text {, AargR, } \Delta \text { farR, pgi (A1G), Psod::tkt, } \\
\text { tal, zWf, opcA, pgl, } \triangle N C g / 1221, \text { Psod::CarAB, Petfu::argGH; } 5 \text { liter bioreactor }\end{array}$ & 92.5 & \multirow[t]{2}{*}{ [9] } \\
\hline & & & Same as above except 1,500 liter bioreactor & 81.2 & \\
\hline \multirow[t]{10}{*}{ ORN } & 1996 & BK533 & $\begin{array}{l}\text { B. ketoglutamicum ATCC } 21092 \text { derived mutant; UV and NTG treatment; } \\
2 \text { liter bioreactor }\end{array}$ & 5.7 & [79] \\
\hline & 2008 & SJ8074 (pEK-CJBD) & $\begin{array}{l}\text { C. glutamicum ATCC } 13032 \triangle \arg F, \triangle \arg R, \triangle p r o B \text {, vector-based overexpression } \\
\text { of } \operatorname{argCJBD}\end{array}$ & 0.179 & {$[80]$} \\
\hline & 2010 & SJ8074 (pEK-P trc::1469) & $\begin{array}{l}\text { C. glutamicum ATCC } 13032 \Delta \operatorname{argF}, \triangle \arg R, \Delta p r o B \text {, vector-based overexpression } \\
\text { of NCgl1469 }\end{array}$ & 0.320 & [54] \\
\hline & 2010 & C. glutamicum & ATCC 13032; proline supplement & 3.295 & [62] \\
\hline & 2011 & $\begin{array}{l}\text { ORN1 (pWWEX1- } \\
\text { araBAD) }\end{array}$ & $\begin{array}{l}\text { C. glutamicum ATCC } 13032 \triangle \arg F \text {, } \Delta \arg R \text {, vector-based overexpression of } \\
\text { araBAD; optimal ARG supplement, arabinose supplement }\end{array}$ & 25.77 & [81] \\
\hline & 2012 & C. glutamicum & ATCC 13032 AargF, $\Delta p r o B, \Delta k g d$ & 4.78 & [82] \\
\hline & 2012 & SJC8399 & C. glutamicum ATCC $\Delta \arg F, \Delta \arg R, \Delta$ Ncgl2399, $\Delta$ Ncgl2905 & 13.16 & [83] \\
\hline & 2013 & $\triangle \mathrm{APRE}::$ rocG & C. glutamicum ATCC $13032 \Delta \arg F, \Delta p r o B, \Delta a r g R, \Delta$ speE:::P tac-M-rocG & 14.84 & [84] \\
\hline & 2013 & $\triangle A P E 6937 R 42$ & $\begin{array}{l}\text { C. glutamicum ATCC } 13032 \Delta \operatorname{argF}, \Delta p r o B, \Delta s p e E, \Delta a r g R ; 70 \text { passages of adaptive } \\
\text { evolution }\end{array}$ & 24.1 & [85] \\
\hline & 2014 & YW6 (pSY233) & $\begin{array}{l}\text { C. glutamicum ATCC } 13032 \Delta p r o B, \triangle \operatorname{argF}, \Delta a r g R, \text { pgi }^{G T G} \text {, zwf }{ }^{\text {ATG }}, \text { Ptkt::Psod, } \\
\text { vector-based overexpression of argCJBD from C. glutamicum ATCC 21831; } \\
5 \text { liter bioreactor }\end{array}$ & 51.5 & {$[86]$} \\
\hline \multirow[t]{2}{*}{ Putrescine } & 2009 & XQ52 (p15SpeC) & $\begin{array}{l}\text { E. coli W3110 } \Delta l a c l, \triangle \text { speE, } \triangle \text { speG, } \triangle a r g l, \triangle p u u P A, \text { PargECBH::Ptrc, Pspef-potE::Ptrc, } \\
\text { PargD::Ptrc, PspeC::Ptrc, ArpoS, vector-based overexpression of speC; } 5 \text { liter } \\
\text { bioreactor }\end{array}$ & 24.2 & [28] \\
\hline & 2010 & ORN1 (pWWEx1-speC) & & 6.0 & {$[50]$} \\
\hline
\end{tabular}


Table 1 ARG, ORN, putrescine and cyanophycin producing strains (Continued)

\begin{tabular}{|c|c|c|c|c|c|}
\hline & & & $\begin{array}{l}\text { C. glutamicum ATCC } 13032 \Delta \text { argF, } \Delta a r g R \text {, vector-based overexpression of speC } \\
\text { from E. coli MG1655; ARG supplement, }\end{array}$ & & \\
\hline & 2012 & $\begin{array}{l}\text { ORN1 (pWWEX1- } \\
\text { speC- }-5_{21}^{\prime} \text {-argF) }\end{array}$ & $\begin{array}{l}\text { C. glutamicum ATCC } 13032 \triangle \operatorname{\Delta argF} \text {, } \Delta a r g R \text {, vector-based overexpression of } \\
\text { speC from E. coli MG1655; ARG auxotrophy rescue by fine-tuned argF } \\
\text { expression via plasmid-addiction system }\end{array}$ & 19.0 & [51] \\
\hline & 2013 & $\begin{array}{l}\text { ORN1 (pWWEX1- } \\
\text { speC- }-5_{21}^{\prime} \text {-argF) }\end{array}$ & $\begin{array}{l}\text { C. glutamicum ATCC } 13032 \Delta \operatorname{argF} \text {, } \Delta \text { argR, vector-based overexpression of speC } \\
\text { from E. coli MG1655; glycerol and glucose as carbon source; ARG supplement }\end{array}$ & 0.855 & [87] \\
\hline \multirow[t]{17}{*}{ Cyanophycin } & 2001 & $\begin{array}{l}\text { C. glutamicum } \\
\text { (pEKO:::cphA) }\end{array}$ & $\begin{array}{l}\text { ATCC 13032, vector-based overexpression of cphA from Synechocystis sp. } \\
\text { Strain PCC6308 }\end{array}$ & 3.6 & [88] \\
\hline & & $\begin{array}{l}\mathrm{H}_{16-\mathrm{PHB}^{-} 4} \\
(\mathrm{pBBR1}: . \mathrm{cphA})\end{array}$ & $\begin{array}{l}\text { R. eutropha DSM } 541 \text { (DSM } 428 \text { derivative), PHA synthesis defect, vector-based } \\
\text { overexpression of cphA from Synechocystis sp. Strain PCC6308 }\end{array}$ & 8.7 & \\
\hline & & E. coli (pSK::cphA) & $\begin{array}{l}\text { TOP 10, vector-based overexpression of cphA from Synechocystis sp. Strain } \\
\text { PCC6308 }\end{array}$ & 26.0 & \\
\hline & & P. putida (pBBR1::cphA) & $\begin{array}{l}\text { KT2440, vector-based overexpression of cphA from Synechocystis sp. Strain } \\
\text { PCC6308 }\end{array}$ & 11.0 & \\
\hline & 2002 & $\begin{array}{l}\text { E. coli }(\mathrm{pMa} / \\
\text { c5-914:.:cphA) }\end{array}$ & $\begin{array}{l}\text { DH1 strain, vector-based overexpression of cphA from Synechocystis sp. PCC6803; } \\
30 \text { liter bioreactor }\end{array}$ & 24.0 & [89] \\
\hline & & & Same as above except 500 liter bioreactor & 21.0 & \\
\hline & 2004 & E. coli $\left(\mathrm{pSK}:: \mathrm{cphA1_{7120 } )}\right.$ & $\begin{array}{l}\text { TOP 10, vector-based overexpression of cphA1 from Anabaena sp. strain } \\
\text { PCC7120 }\end{array}$ & 21.0 & [90] \\
\hline & & $\begin{array}{l}\text { GPp104 (pBBR1MCS-2:: } \\
\text { cphA1 }\end{array}$ & $\begin{array}{l}\text { P. putida KT } 2440 \text { mutant, vector-based overexpression of cphA1 from } \\
\text { Anabaena sp. strain PCC7120 }\end{array}$ & 24.0 & \\
\hline & & $\begin{array}{l}\mathrm{H}_{16-\mathrm{PHB}^{-} 4} \\
(\mathrm{pBBR} 1 \mathrm{MCS}-2:: \\
\left.\text { CphA1 }_{7120}\right)\end{array}$ & $\begin{array}{l}\text { R. eutropha DSM } 541 \text { (DSM } 428 \text { derivative), PHA synthesis defect, vector-based } \\
\text { overexpression of cphA1 from Anabaena sp. strain PCC7120 }\end{array}$ & 22.0 & \\
\hline & 2005 & A. calcoaceticus & ATCC 33305, flask cultivation; ARG supplement & 46.0 & [91] \\
\hline & 2006 & $\begin{array}{l}\text { R. eutropha (pBBR1MCS- } \\
\text { 2::cphAveda) }\end{array}$ & $\begin{array}{l}\text { DSM } 541 \text { derivative, } \mathrm{H}_{16-\mathrm{PHB}^{-} 4} 4 \text { deda, vector-based overexpression of } c p h A \text { from } \\
\text { Synechocystis sp. Strain PCC6308; eda-dependent plasmid-addiction system; } \\
\text { flask cultivation }\end{array}$ & 40.0 & [92] \\
\hline & & & Same as above except 30 liter bioreactor & 35.8 & \\
\hline & & & Same as above except 500 liter bioreactor & 32.0 & \\
\hline & 2011 & $\begin{array}{l}\text { E. coli (pCOLADuet-1:: } \\
\text { cphAC595S::.dapLss) }\end{array}$ & $\begin{array}{l}\text { HMS174(DE3) } \triangle \text { dapE, plasmid-addiction system using dapL from Synechocystis sp. } \\
\text { Strain PCC6308, C595S mutant cphA from Synechocystis sp. Strain PCC6308; } \\
\text { flask cultivation }\end{array}$ & 42.0 & [93] \\
\hline & & & Same as above except 25 liter bioreactor & 14.1 & \\
\hline & & & Same as above except 400 liter bioreactor & 18.0 & \\
\hline & 2012 & 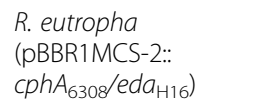 & $\begin{array}{l}\text { DSM } 428 \text { mutant, } \mathrm{H} 16-\mathrm{PHB}^{-} 4 \text { Seda, vector-based overexpression of cphA from } \\
\text { Synechocystis sp. Strain PCC6308, eda-dependent plasmid-addiction system; } \\
30 \text { liter bioreactor }\end{array}$ & 47.5 & [94] \\
\hline
\end{tabular}

Strains that have been reported to produce ARG, ORN, putrescine and cyanophycin are listed in the order of year for each compound. The relevant genetic information and production titers are shown. All cyanophycin production titers are given in a different unit scale (w/w \%) than the rest which are given in $\mathrm{g} / \mathrm{liter}$ 5HUR, 5-hydroxyuridine; TRA, triazolealanine; 6FTP, 6-fluorotryptophan; 2TU, 2-thiouracil; 5FU, 5-fluorouracil; NIM, polyoxyethylene stearylamine.

of ARG to microorganisms and to remove feedback inhibition by ARG [9]. Historically, the random mutation approach had been used in various prokaryotic and eukaryotic strains including B. subtilis [18,73,74], Serratia marcescens [73], Micrococcus sodonensis [73], Norcadia corynebacteroides [73], N. rubra [73], Saccharomyces cerevisiae [73], Candida tropicalis [73], C. glutamicum [72], C. crenatum [76], Brevibacterium flavum [75], B. ketoglutamicum [75], C. lilium [75], Arthrobacter paraffineus [75] and Microbacterium ammoniaphilum [73,75] to produce ARG. The trend later shifted toward using GLU overproducing C. glutamicum strain and its related species $C$. crenatum as base strains, which led to industrial level ARG titers. More importantly, the random mutation method is now used in synergistic combination with high-throughput molecular tools which enables systems metabolic engineering for industrial microbial strain development.

The strategies for rationally designing ARG overproducer typically consist of (1) removal of feedback inhibition, (2) overexpression of the biosynthetic genes (e.g., the arg operon) and/or removal of the repressors (e.g., $\operatorname{argR}$ and farR), (3) increasing NADPH pool required for ARG biosynthesis, (4) increasing carbamoyl phosphate pool by 
overexpression of $\operatorname{car} A B$ operon and (5) deletion of exporter for GLU encoded by $N C g l 1221$. For example, reverse engineering approach was taken to the wild-type $C$. glutamicum ATCC 13032 strain for deleting argR and introducing $\mathrm{A} 26 \mathrm{~V}$ and M31V mutations in ArgB in order to alleviate feedback inhibition [47]. This is an important study because it presented the first genetically defined and not randomly mutated strain for ARG production and the engineered strain produced $52 \mathrm{~g} /$ liter of ARG [47]. Plasmid-based engineering system has also been explored. Overexpression of a bacterial hemoglobin from Vitreoscilla in C. crenatum SYPA 5-5 for increased dissolved oxygen availability led to the production of 35.9 g/liter ARG [77]. Plasmid-based overexpression of the $\operatorname{argCJBDFRGH}$ cluster or argJ alone in C. crenatum SYPA 5-5 also led to enhanced ARG production, reaching $45.3 \mathrm{~g} /$ liter or $42.4 \mathrm{~g} /$ liter, respectively $[34,78]$. A possible explanation for little difference in ARG titer here despite the different number of gene overexpression is probably because different cultivation conditions were used (e.g., different temperatures).

Along the same line, a recent systems metabolic engineering study led to a very successful production of ARG at the industrial-scale [9]. C. glutamicum ATCC 21831 was initially treated with CVN and AHX in order to increase its ARG tolerance and subjected to stepwise strain development. The $\arg R$ and $\operatorname{far} R$ genes were deleted in order to relieve negative regulation on ARG biosynthesis. Next, in order to improve the NADPH pool, the pentose phosphate pathway (PPP) flux was enhanced by reducing the pgi expression through replacing ATG start codon with GTG, and overexpressing the major PPP operon consisting the $t k t, t a l, z w f, o p c A$ and $p g l$ by replacing the native promoter with the strong sod promoter. Finally the promoters for $\operatorname{car} A B$ and $\arg G H$ operons were also changed in order to optimize fluxes toward the ARG biosynthesis and the Ncgl1221 gene, encoding the GLU exporter, was deleted. As a result, the final constructed strain produced $92.5 \mathrm{~g} / \mathrm{liter}$ and $81.2 \mathrm{~g} /$ liter of ARG at the laboratory-scale and at the industrialscale fermentations, respectively [9]. This work is a good example of systems metabolic engineering for developing a microbial strain capable of overproducing ARG to the level and performance suitable for industrialscale production.

\section{Metabolic engineering for L-ornithine production}

The ARG-derivative, ORN, has also been produced by microbial fermentation. Both the strategies of random mutagenesis [79] and systems metabolic engineering have been employed for developing strains (Figure 2). In rationally designing an ORN producer, knocking out the competing branches to redirect carbon flux to ORN pathway is an important and common strategy.
Specifically, the strategies of PRO supplement [62], ARG supplement [81], vector-based overexpression of $\operatorname{argCJBD}$ [80], NCgl1469 overexpression [54], overexpression of rocG from B. subtilis [84], $\triangle \operatorname{argF}$ [80-85], $\triangle$ proB [82,84,85], $\Delta$ speE [84,85], $\triangle \operatorname{argR}[81,83-85]$, $\Delta N C g l 2399$ [83], $\Delta N C g l 2905$ [83], and $\Delta k g d$ [82] have been employed for developing strains for ORN overproduction (Table 1).

The strategies for the development of ORN producers are similar to those employed for ARG producers except auxotrophy rescue by supplements is additionally used. Here, $\triangle a r g F$ and $\triangle p r o B$ are often included in order to disrupt OTCase and gamma-glutamyl kinase, respectively [80-85]. Although this strategy leads to higher ORN titer, it makes the strain auxotrophic for ARG and PRO since their biosynthesis is disrupted [62,81]. Another common strategies are deletion of the repressor $(\triangle \operatorname{argR})[81,83-85]$ as in ARG strain cases, and overexpression of the biosynthetic genes (e.g., $\operatorname{argCJBD)}$ using plasmids [80]. Overexpression of putative biosynthetic genes can also be a strategy for ORN production. It has been reported that overexpression of putative NAGS encoded by $\mathrm{NCgl1469}$ leads to increased ORN production [54] while others claim Ncgl1469 as diaminopentane acetyltransferase [95]. It is possible that Ncgl1469 potentially encodes a broad-substrate acetyltransferase that has not been characterized in detail. The TCA cycle flux can also be reduced by deleting 2-oxoglutarate dehydrogenase complex $(\mathrm{ODHC})$ for the enhanced production of ORN [82].

Increasing the NADPH pool also improves ORN production. The use of $B$. subtilis rocG which encodes NAD-dependent glutamate dehydrogenase allows conversion of $\alpha-K G$ to GLU in an NADPH-independent manner and leaves more NADPH for ORN biosynthesis [84]. Increasing the NADPH level can also be achieved by inactivating two putative gluconate kinases (gntK) encoded by NCgl2399 and NCgl2905 [83]. Overexpression of the ATP-dependent NAD kinase encoded by $p p n K$ also leads to enhanced ORN production, while overexpression of glucose-6-phosphate dehydrogenase encoded by $z w f$ and 6-phosphogluconate dehydrogenase encoded by gnd does not do the same [85]. A possible explanation is that plasmid-based overexpression of $z w f$ and gnd causes cellular burdens because chromosomallevel overexpression has shown improvement in ORN titer [86]. An indirectly associated pathway for spermidine biosynthesis can also be deleted for enhanced ORN production, yet the reason behind it has not been explained [85]. Combining the aforementioned strategies, a recently developed strain was reported to produce $51.5 \mathrm{~g} / \mathrm{L}$ of ORN [86]. In this strain, the PPP flux was enhanced by changing the $t k t$ promoter and the start codons of $p g i$ and $z w f$. The $\operatorname{argCJBD}$ cluster from $C$. 


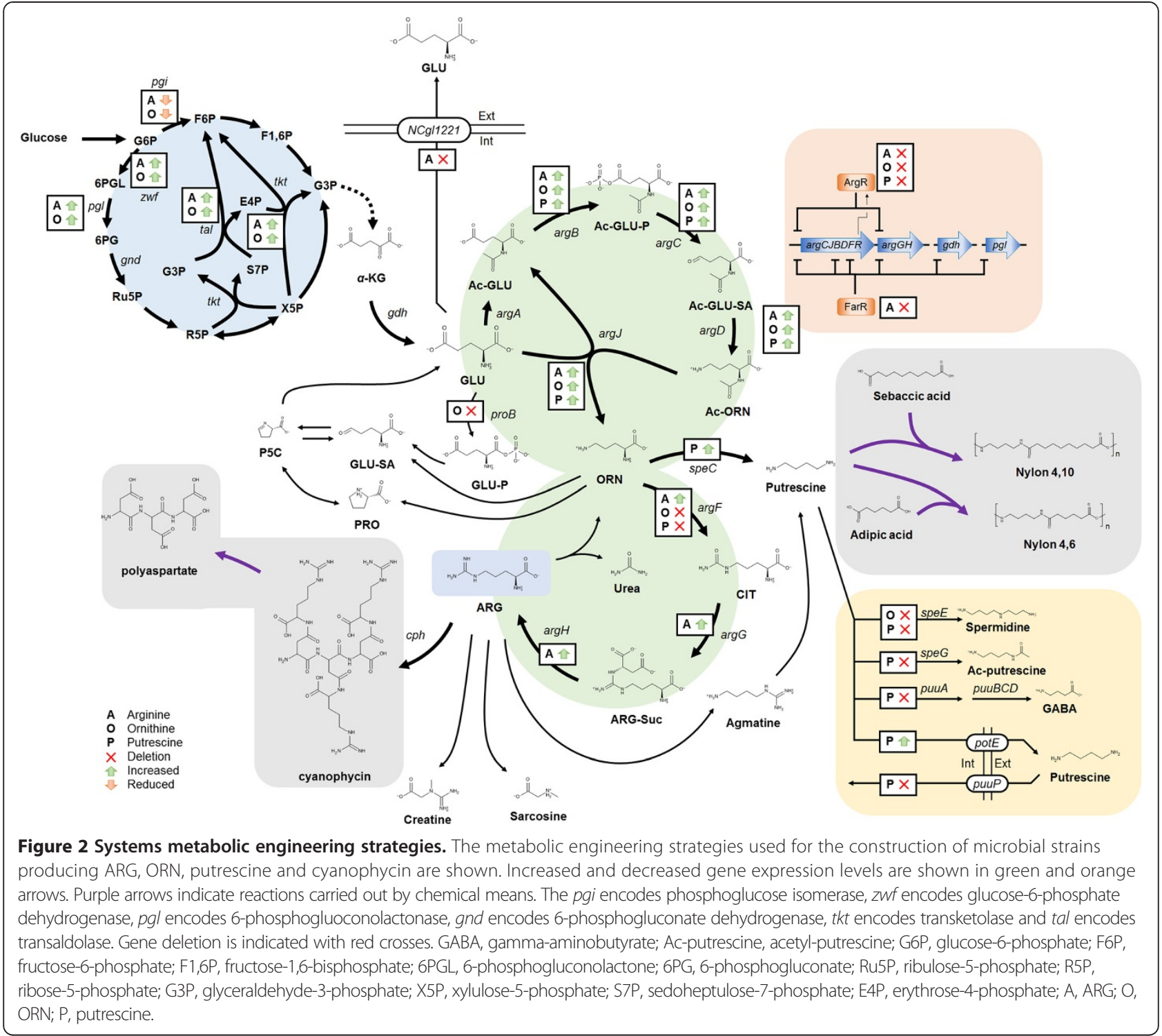

glutamicum ATCC 21831 was overexpressed and $\arg F$, proB and $\arg R$ were deleted.

\section{Metabolic engineering for putrescine production}

Putrescine (1,4-diaminobutane) can be produced by metabolic engineering of ARG related pathways. The major chassis organisms that have been employed are $E$. coli [28] and C. glutamicum [50]. While the putrescine biosynthesis pathway is not well known in C. glutamicum, it is a desirable host as it produces ORN efficiently and tolerates putrescine better than E. coli $[28,50]$. Although putrescine biosynthesis can be alternatively achieved via agmatine pathway (Figure 2), the ODC pathway was shown to be more efficient than the agmatine pathway [50]. In addition to the strategies employed for developing ARG and ORN producers described in prior sections, engineering the transporters are the additional strategies for designing cell-factories for putrescine production.

Putrescine can be synthesized from ORN by a single reaction carried out by ornithine decarboxylase (ODC) encoded by speC (Figure 2). The ODC from E. coli is often used since the metabolic pathway in C. glutamicum for putrescine has not been identified [50]. To develop a putrescine producing $C$. glutamicum strain, the arginine repressor encoded by $\arg R$ should be inactivated as in the ARG and ORN overproducing strains [50,51]. While disruption of OTCase is also a strategy for improving ORN pool, this makes the strain to become an ARG auxotroph [50]. Here, the ARG auxotrophy caused by $\triangle \arg F$ can be overcome by introducing a plasmid expressing argF which is also fine-tuned [51]. The use of this strategy is an example of plasmidaddiction system and it circumvents the undesirable use 
of antibiotic as well because cell viability becomes plasmid-dependent [96]. While engineering of the putrescine transport system in C. glutamicum would further enhance its production, this strategy has yet been applied only in E. coli [28]. Along with the overexpression of putrescine/ornithine antiporter (encoded by potE) and deletion of putrescine importer (encoded by puuP), the competitive and degradation routes were deleted in the putrescine producing E. coli XQ52 strain [28]. Chromosomal deletion of puuA encoding glutamate-putrescine ligase, spe $E$ encoding spermidine synthase, spe $G$ encoding spermidine acetyltransferase, and argI encoding one of the monomers for OTCase improved putrescine production. The native promoters of the key biosynthetic genes ( $\operatorname{argECBH}$ operon, $\operatorname{argD}$ and $s p e C$ ) were changed to stronger promoters and the repressor $\operatorname{argR}$ was deleted. The rpoS gene encoding the stress-responsive RNA polymerase sigma factor was also deleted, which led to the development of the final strain capable of producing $24.2 \mathrm{~g} /$ liter of putrescine [28]. While the highest putrescine producing strain reported is so far $E$. coli, further engineering of ORN overproducing C. glutamicum strain will likely led to the development of a more efficient putrescine producer due to its high-tolerance to putrescine [86].

\section{Metabolic engineering for cyanophycin production}

Cyanophycin was first discovered more than a century ago in cyanobacteria as a carbon and nitrogen storage compound [97]. Cyanophycin has been recently attracting attention because it can be chemically reduced to make polyaspartate. Polyaspartate is a completely biodegradable polymer [88], which can be used as a polyacrylate substitute, an additive polymer in the oil field [98], and as a polymer suitable for water treatments and medical applications [99]. Additionally, cyanophycin can also be used to produce isotope-labeled ARG [100].

Cyanophycin is composed of equimolar amount of ARG and L-aspartate (ASP). Cyanophycin synthetase encoded by $c p h A$ carries out the reaction of polymerizing ASP and ARG (Figure 2). Various strains including P. putida $[88,90]$, R. eutropha $[88,92,94]$, C. glutamicum [88] and E. coli $[88,89,93]$ have been employed for the production of cyanophycin through the heterologous expression of cphA from Synechocystis sp. PCC6803 [89] or Anabaena sp. strain PCC7120 [90]. Acinetobacter calcoaceticus $[91,101]$ has also been used to produce cyanophycin using the endogenous cphA gene [91,101]. The metabolic engineering strategies employed include the use of mutants incapable of accumulating polyhydroxyalkanoates $[88,92,94]$, plasmid-addiction system using eda [92,94] or dapE [93] deleted strains, and the use of CphA variant having C595S mutation [102]. There was an interesting report on the use of 2-keto-3-deoxy-6-phosphogluconate aldolase encoded by eda, which is required in gluconate and fructose metabolism. The use of this gene for plasmidaddiction system in $\Delta e d a$ strain circumvents the need to use antibiotics in large-scale cultivation. The 30, 400 and 500 liter-scale bioreactors have been used for the largescale production of cyanophycin, which was followed by successful purification; at the end, the titer corresponding to $750 \mathrm{~g}$ of cyanophycin with $75 \%$ extraction yield have been reported [89].

\section{Conclusions}

With increasing volumes of biological information and availability of high-throughput molecular tools, systems metabolic engineering has become an essential strategy for developing microbial strains overproducing ARG, ORN, putrescine and cyanophycin. Systems metabolic engineering obviously requires thorough understanding of the metabolism and gene regulatory circuits towards the production of desired products. The strategies of knocking out the negative regulatory mechanisms, amplifying the fluxes of pathways towards the product formation, deleting the byproducts forming pathways, and increasing the exporters while reducing the importers have been combined to develop microbial strains capable of producing ARG and related products. Such engineering strategies have been successfully applied to rationally construct a high-performance strain which works efficiently not only at the laboratory-scale but also at the semi industrial-scale fermentation. New tools of systems metabolic engineering are continuously emerging. For example, further metabolic engineering of the strain based on the sRNA technology can be envisioned to rapidly develop high-level producers. The strategies described here will be useful for developing microbial strains capable of more efficiently producing ARG and related products, including not only those mentioned in this paper but also other derivatives including sarcosine, creatine, agmatine and creatinine.

\section{Abbreviations \\ ARG: L-arginine; LYS: L-lysine; TRP: L-tryptophan; VAL: L-valine; THR: L- threonine; ALA: L-alanine; ASP: L-aspartate; ORN: L-ornithine; PRO: L-proline; CIT: L-citrulline; GLU: L-glutamate; Ac-ORN: N-acetylornithine; Ac-CIT: N- acetylcitrulline; Ac-CoA: Acetyl coenzyme A; $a$-KG: $a$-ketoglutarate; OATase: Ornithine acetyltransferase; OTCase: Ornithine cabamoyltransferase; NAGS: N-acetylglutamate synthase; NAGK: N-acetylglutamate kinase; AOase: Acetylornithinase; AOTCase: Acetylornithine carbamoyltransferase; ODC: Ornithine decarboxylase; PPP: Pentose phosphate pathway; AHX: Arginine hydroxamate; CVN: Canavanine; 6 AU: 6-azauracil; TA: 2- thiazolealanine; SG: Sulfaguanine; NTG: N-methyl-N'-nitro-N-nitrosoguanidine; NADPH: Nicotinamide adenine dinucleotide phosphate; ATP: Adenosine triphosphate.}

Competing interests

The authors declare that they have no competing interests.

Authors' contributions

SY Lee conceived the project. SY Lee and JH Shin wrote the manuscript. Both authors read and approved the final manuscript, 


\section{Acknowledgements}

Authors thank Dr. H.U. Kim for critically reading the manuscript. This work was supported by the Technology Development Program to Solve Climate Changes on Systems Metabolic Engineering for Biorefineries from the Ministry of Science, ICT and Future Planning (MSIP) through the National Research Foundation (NRF) of Korea (NRF-2012M1A2A2026556).

\section{Author details}

${ }^{1}$ Metabolic and Biomolecular Engineering National Research Laboratory, Department of Chemical and Biomolecular Engineering (BK21 Plus Program), Center for Systems and Synthetic Biotechnology, Institute for the BioCentury, KAIST, 291 Daehak-ro, Yuseong-gu, Daejeon 305-701, Republic of Korea. ${ }^{2}$ BioProcess Engineering Research Center, KAIST, Daejeon 305-701, Republic of Korea. ${ }^{3}$ Biolnformatics Research Center, KAIST, Daejeon 305-701, Republic of Korea.

Received: 7 October 2014 Accepted: 15 November 2014 Published online: 03 December 2014

\section{References}

1. Albaroth J, Muller OA, Schopohl J, Vonwerder K: Arginine stimulates growth-hormone secretion by suppressing endogenous somatostatin secretion. J Clin Endocrinol Metab 1988, 67:1186-1189.

2. Davis SL: Plasma levels of prolactin, growth-hormone, and insulin in sheep following infusion of arginine, leucine and phenylalanine. Endocrinology 1972, 91:549-555.

3. Thams P, Capito K: L-Arginine stimulation of glucose-induced insulin secretion through membrane depolarization and independent of nitric oxide. Eur J Endocrinol 1999, 140:87-93.

4. Palmer JP, Benson JW, Walter RM, Ensinck JW: Arginine-stimulated acute phase of insulin and glucagon-secretion in diabetic subjects. J Clin Invest 1976, 58:565-570.

5. Jobgen WJ, Meininger CJ, Jobgen SC, Li P, Lee MJ, Smith SB, Spencer TE, Fried SK, Wu GY: Dietary L-arginine supplementation reduces white fat gain and enhances skeletal muscle and brown fat masses in diet-induced obese rats. J Nutr 2009, 139:230-237.

6. Barbul A, Lazarou SA, Efron DT, Wasserkrug HL, Efron G: Arginine enhances wound-healing and lymphocyte immune-responses in humans. Surgery 1990, 108:331-337.

7. Rogers $N E$, Ignarro $L J$ : Constitutive nitric-oxide synthase from cerebellum is reversibly inhibited by nitric-oxide formed from L-arginine. Biochem Biophys Res Commun 1992, 189:242-249.

8. Ignarro LJ, Cirino G, Casini A, Napoli C: Nitric oxide as a signaling molecule in the vascular system: an overview. J Cardiovasc Pharmacol 1999, 34:879-886.

9. Park SH, Kim HU, Kim TY, Park JS, Kim SS, Lee SY: Metabolic engineering of Corynebacterium glutamicum for L-arginine production. Nat Commun 2014, 5:4618.

10. Chen N, Du J, Liu H, Xu QY: Elementary mode analysis and metabolic flux analysis of L-glutamate biosynthesis by Corynebacterium glutamicum. Ann Microbiol 2009, 59:317-322.

11. Becker J, Zelder O, Hafner S, Schroder H, Wittmann C: From zero to herodesign-based systems metabolic engineering of Corynebacterium glutamicum for L-lysine production. Metab Eng 2011, 13:159-168.

12. Leuchtenberger W, Huthmacher K, Drauz K: Biotechnological production of amino acids and derivatives: current status and prospects. Appl Microbiol Biotechnol 2005, 69:1-8.

13. Park JH, Lee KH, Kim TY, Lee SY: Metabolic engineering of Escherichia coli for the production of L-valine based on transcriptome analysis and in silico gene knockout simulation. Proc Natl Acad Sci U S A 2007, 104:7797-7802.

14. Lee KH, Park JH, Kim TY, Kim HU, Lee SY: Systems metabolic engineering of Escherichia coli for L-threonine production. Mol Syst Biol 2007, 3:149.

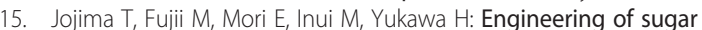
metabolism of Corynebacterium glutamicum for production of amino acid L-alanine under oxygen deprivation. Appl Microbiol Biotechnol 2010, 87:159-165

16. Becker J, Wittmann C: Bio-based production of chemicals, materials and fuels - Corynebacterium glutamicum as versatile cell factory. Curr Opin Biotechnol 2012, 23:631-640.

17. Becker J, Wittmann C: Systems and synthetic metabolic engineering for amino acid production - the heartbeat of industrial strain development. Curr Opin Biotechnol 2012, 23:718-726.
18. Kisumi M, Kato J, Sugiura M, Chibata I: Production of L-arginine by arginine hydroxamate-resistant mutants of Bacillus subtilis. App/ Microbiol 1971, 22:987-991

19. Udaka S, Kinoshita S: Studies on L-ornithine fermentation I. The biosynthetic pathway of L-ornithine in Micrococcus glutamicum. J Gen App/ Microbiol 1958, 4:272-282.

20. Lee J, Jang YS, Choi SJ, Im JA, Song H, Cho JH, Seung DY, Papoutsakis ET, Bennett GN, Lee SY: Metabolic engineering of Clostridium acetobutylicum ATCC 824 for isopropanol-butanol-ethanol fermentation. Appl Environ Microbiol 2012, 78:1416-1423.

21. Jang YS, Malaviya A, Lee J, Im JA, Lee SY, Lee J, Eom MH, Cho JH, Seung DY: Metabolic engineering of Clostridium acetobutylicum for the enhanced production of isopropanol-butanol-ethanol fuel mixture. Biotechnol Prog 2013, 29:1083-1088.

22. Paddon CJ, Westfall PJ, Pitera DJ, Benjamin K, Fisher K, McPhee D, Leavell MD, Tai A, Main A, Eng D, Polichuk DR, Teoh KH, Reed DW, Treynor T, Lenihan J, Fleck M, Bajad S, Dang G, Dengrove D, Diola D, Dorin G, Ellens KW, Fickes S, Galazzo J, Gaucher SP, Geistlinger T, Henry R, Hepp M, Horning T, labal T, et al: High-level semi-synthetic production of the potent antimalarial artemisinin. Nature 2013, 496:528-532.

23. Jung YK, Kim TY, Park SJ, Lee SY: Metabolic engineering of Escherichia coli for the production of polylactic acid and its copolymers. Biotechnol Bioeng 2010, 105:161-171.

24. Park SJ, Kim EY, Noh W, Park HM, Oh YH, Lee SH, Song BK, Jegal J, Lee SY: Metabolic engineering of Escherichia coli for the production of 5-aminovalerate and glutarate as C5 platform chemicals. Metab Eng 2013, 16:42-47.

25. Jang YS, Kim B, Shin JH, Choi YJ, Choi S, Song CW, Lee J, Park HG, Lee SY: Bio-based production of C2-C6 platform chemicals. Biotechnol Bioeng 2012, 109:2437-2459.

26. Yim H, Haselbeck R, Niu W, Pujol-Baxley C, Burgard A, Boldt J, Khandurina J, Trawick JD, Osterhout RE, Stephen R, Estadilla J, Teisan S, Schreyer HB, Andrae S, Yang TH, Lee SY, Burk MJ, Van Dien S: Metabolic engineering of Escherichia coli for direct production of 1,4-butanediol. Nat Chem Biol 2011, 7:445-452

27. Xia XX, Qian ZG, Ki CS, Park YH, Kaplan DL, Lee SY: Native-sized recombinant spider silk protein produced in metabolically engineered Escherichia coli results in a strong fiber. Proc Natl Acad Sci U S A 2010, 107:14059-14063.

28. Qian ZG, Xia XX, Lee SY: Metabolic engineering of Escherichia coli for the production of putrescine: a four carbon diamine. Biotechnol Bioeng 2009 104:651-662.

29. Qian ZG, Xia XX, Lee SY: Metabolic engineering of Escherichia coli for the production of cadaverine: a five carbon diamine. Biotechnol Bioeng 2011 108:93-103.

30. Na D, Yoo SM, Chung H, Park H, Park JH, Lee SY: Metabolic engineering of Escherichia coli using synthetic small regulatory RNAs. Nat Biotechnol 2013, 31:170-174.

31. Meneguello MO, Mendonca JR, Lancha AH Jr, Costa Rosa LF: Effect of arginine, ornithine and citrulline supplementation upon performance and metabolism of trained rats. Cell Biochem Funct 2003, 21:85-91.

32. Kalinowski J, Bathe B, Bartels D, Bischoff N, Bott M, Burkovski A, Dusch N, Eggeling L, Eikmanns BJ, Gaigalat L, Goesmann A, Hartmann M, Huthmacher K, Kramer R, Linke B, McHardy AC, Meyer F, Mockel B, Pfefferle W, Puhler A, Rey DA, Ruckert C, Rupp O, Sahm H, Wendisch VF, Wiegrabe I, Tauch A: The complete Corynebacterium glutamicum ATCC 13032 genome sequence and its impact on the production of L-aspartate-derived amino acids and vitamins. J Biotechnol 2003, 104:5-25.

33. Lu CD: Pathways and regulation of bacterial arginine metabolism and perspectives for obtaining arginine overproducing strains. Appl Microbiol Biotechnol 2006, 70:261-272.

34. Dou WF, Xu MJ, Cai DM, Zhang XM, Rao ZM, Xu ZH: Improvement of $\mathrm{L}$-arginine production by overexpression of a bifunctional ornithine acetyltransferase in Corynebacterium crenatum. Appl Biochem Biotechnol 2011, 165:845-855.

35. Glansdorff N, Xu Y: Microbial Arginine Biosynthesis: Pathway, Regulation and Industrial Production. In Amino Acid Biosynthesis - Pathways, Regulation and Metabolic Engineering, Volume Volume 5. Edited by Wendisch V. Heidelberg, Germany: Springer; 2007:219-257.

36. Vyas S, Maas WK: Feedback inhibition of acetylglutamate synthetase by arginine in Escherichia coli. Arch Biochem Biophys 1963, 100:542-546. 
37. Sakanyan V, Charlier D, Legrain C, Kochikyan A, Mett I, Pierard A, Glansdorff $\mathrm{N}$ : Primary structure, partial purification and regulation of key enzymes of the acetyl cycle of arginine biosynthesis in Bacillus stearothermophilus: dual function of ornithine acetyltransferase. J Gen Microbiol 1993, 139:393-402.

38. Morizono H, Cabrera-Luque J, Shi DS, Gallegos R, Yamaguchi S, Yu XL, Allewell NM, Malamy MH, Tuchman M: Acetylornithine transcarbamylase: a novel enzyme in arginine biosynthesis. J Bacterio/ 2006, 188:2974-2982.

39. Haas D, Leisinge T, Kurer V: N-acetylglutamate synthetase of Pseudomonas aeruginosa - an assay in vitro and feedback inhibition by arginine. Eur J Biochem 1972, 31:290-295

40. Picard FJ, Dillon JR: Cloning and organization of seven arginine biosynthesis genes from Neisseria gonorrhoeae. J Bacterio/ 1989, 171:1644-1651.

41. Harris BZ, Singer M: Identification and characterization of the Myxococcus xanthus argE gene. J Bacteriol 1998, 180:6412-6414.

42. Marc F, Weigel P, Legrain C, Almeras Y, Santrot M, Glansdorff N, Sakanyan V: Characterization and kinetic mechanism of mono- and bifunctional ornithine acetyltransferases from thermophilic microorganisms. Eur J Biochem 2000, 267:5217-5226.

43. Sakanyan V, Kochikyan A, Mett I, Legrain C, Charlier D, Pierard A, Glansdorff $\mathrm{N}$ : A reexamination of the pathway for ornithine biosynthesis in a Thermophilic and two mesophilic Bacillus Species. J Gen Microbiol 1992, 138:125-130.

44. Udaka S: Pathway-specific pattern of control of arginine biosynthesis in bacteria. J Bacteriol 1966, 91:617-621.

45. Martin PR, Mulks MH: Sequence analysis and complementation studies of the $\mathrm{arg} J$ gene encoding ornithine acetyltransferase from Neisseria gonorrhoeae. J Bacteriol 1992, 174:2694-2701.

46. Hindle Z, Callis R, Dowden S, Rudd BA, Baumberg S: Cloning and expression in Escherichia coli of a Streptomyces coelicolor A3(2) $\operatorname{argCJB}$ gene cluster. Microbiology 1994, 140:311-320.

47. Ikeda M, Mitsuhashi S, Tanaka K, Hayashi M: Reengineering of a Corynebacterium glutamicum L-arginine and L-citrulline producer. Appl Environ Microbiol 2009, 75:1635-1641

48. Xu Y, Labedan B, Glansdorff N: Surprising arginine biosynthesis: a reappraisal of the enzymology and evolution of the pathway in microorganisms. Microbiol Mol Biol Rev 2007, 71:36-47.

49. Yim SH, Jung S, Lee SK, Cheon Cl, Song E, Lee SS, Shin J, Lee MS: Purification and characterization of an arginine regulatory protein, ArgR, in Corynebacterium glutamicum. J Ind Microbiol Biotechnol 2011 38:1911-1920

50. Schneider J, Wendisch VF: Putrescine production by engineered Corynebacterium glutamicum. Appl Microbiol Biotechnol 2010, 88:859-868.

51. Schneider J, Eberhardt D, Wendisch VF: Improving putrescine production by Corynebacterium glutamicum by fine-tuning ornithine transcarbamoylase activity using a plasmid addiction system. Appl Microbiol Biotechno/ 2012, 95:169-178.

52. Sakanyan $V$, Petrosyan $P$, Lecocq M, Boyen A, Legrain C, Demarez $M$ Hallet JN, Glansdorff N: Genes and enzymes of the acetyl cycle of arginine biosynthesis in Corynebacterium glutamicum: enzyme evolution in the early steps of the arginine pathway. Microbiology 1996, 142:99-108.

53. Petri K, Walter F, Persicke M, Ruckert C, Kalinowski J: A novel type of $\mathrm{N}$-acetylglutamate synthase is involved in the first step of arginine biosynthesis in Corynebacterium glutamicum. BMC Genomics 2013, 14:713.

54. Hwang GH, Cho JY: Identification of a suppressor gene for the arginineauxotrophic argJ mutation in Corynebacterium glutamicum. J Ind Microbiol Biotechnol 2010, 37:1131-1136.

55. Xu Y, Glansdorff N, Labedan B: Bioinformatic analysis of an unusual gene-enzyme relationship in the arginine biosynthetic pathway among marine gamma proteobacteria: implications concerning the formation of $\mathrm{N}$-acetylated intermediates in prokaryotes. BMC Genomics 2006, 7:4.

56. Errey JC, Blanchard JS: Functional characterization of a novel ArgA from Mycobacterium tuberculosis. J Bacteriol 2005, 187:3039-3044.

57. Shi D, Sagar , Jin Z, Yu X, Caldovic L, Morizono H, Allewell NM, Tuchman $\mathrm{M}$ : The crystal structure of $\mathrm{N}$-acetyl-L-glutamate synthase from Neisseria gonorrhoeae provides insights into mechanisms of catalysis and regulation. J Biol Chem 2008, 283:7176-7184.

58. Cunin R, Glansdorff N, Pierard A, Stalon V: Biosynthesis and metabolism of arginine in bacteria. Microbiol Rev 1986, 50:314-352.

59. Xu MJ, Rao ZM, Dou WF, Jin J, Xu ZH: Site-directed mutagenesis studies on the L-arginine-binding sites of feedback inhibition in N-Acetyl-I- glutamate Kinase (NAGK) from Corynebacterium glutamicum. Curr Microbiol 2012, 64:164-172

60. Ramon-Maiques S, Fernandez-Murga ML, Gil-Ortiz F, Vagin A, Fita I, Rubio V: Structural bases of feed-back control of arginine biosynthesis, revealed by the structures of two hexameric $\mathrm{N}$-acetylglutamate kinases, from Thermotoga maritima and Pseudomonas aeruginosa. J Mol Biol 2006, 356:695-713.

61. Theron G, Reid SJ: ArgR-promoter interactions in Corynebacterium glutamicum arginine biosynthesis. Biotechnol Appl Biochem 2011, 58:119-127.

62. Lee SY, Cho JY, Lee HJ, Kim YH, Min J: Enhancement of ornithine production in proline-supplemented Corynebacterium glutamicum by ornithine cyclodeaminase. J Microbiol Biotechnol 2010, 20:127-131.

63. Hanssler E, Muller T, Jessberger N, Volzke A, Plassmeier J, Kalinowski J, Kramer R, Burkovski A: FarR, a putative regulator of amino acid metabolism in Corynebacterium glutamicum. Appl Microbiol Biotechnol 2007, 76:625-632

64. Lee SY, Park JM, Lee JH, Chang ST, Park JS, Kim YH, Min J: Interaction of transcriptional repressor ArgR with transcriptional regulator FarR at the $\arg B$ promoter region in Corynebacterium glutamicum. Appl Environ Microbiol 2011, 77:711-718.

65. Lee SY, Shin HS, Park JS, Kim YH, Min J: Proline reduces the binding of transcriptional regulator ArgR to upstream of $\operatorname{argB}$ in Corynebacterium glutamicum. Appl Microbiol Biotechnol 2010, 86:235-242.

66. Savchenko A, Weigel P, Dimova D, Lecoca M, Sakanyan V: The Bacillus stearothermophilus $\arg C J B D$ operon harbours a strong promoter as evaluated in Escherichia coli cells. Gene 1998, 212:167-177.

67. Piette J, Cunin R, Boyen A, Charlier D, Crabeel M, Vanvliet F, Glansdorff N, Squires $C$, Squires $C L$ : The regulatory region of the divergent $\operatorname{argECBH}$ operon in Escherichia coli K-12. Nucleic Acids Res 1982, 10:8031-8048.

68. Charlier D, Roovers M, Vanvliet F, Boyen A, Cunin R, Nakamura Y, Glansdorff $\mathrm{N}$, Pierard A: Arginine regulon of Escherichia coli K-12: A study of repressor operator interactions and of in vitro binding affinities versus in vivo repression. J Mol Biol 1992, 226:367-386.

69. Bringel F, Frey L, Boivin S, Hubert JC: Arginine biosynthesis and regulation in Lactobacillus plantarum: the carA gene and the $\operatorname{argCJBDF}$ cluster are divergently transcribed. J Bacterio/ 1997, 179:2697-2706

70. RodriguezGarcia A, Ludovice M, Martin JF, Liras P: Arginine boxes and the $\arg R$ gene in Streptomyces clavuligerus: evidence for a clear regulation of the arginine pathway. Mol Microbiol 1997, 25:219-228.

71. Walker JB: Canavanine and homoarginine as antimetabolites of arginine and lysine in yeast and algae. J Biol Chem 1955, 212:207-215.

72. Nakayama K, Yoshida H: Fermentative production of L-arginine. Agric Biol Chem 1972, 36:1675-1684.

73. Yoshida H, Araki K, Nakayama K: Fermentative production of L-arginine. 5. $\mathrm{L}$-Arginine production by arginine analog-resistant mutants of microorganisms. Agric Biol Chem 1981, 45:959-963.

74. Kato J, Kisumi M, Takagi T, Chibata I: Increase in arginine and citrulline production by 6-azauracil-resistant mutants of Bacillus subtilis. Appl Environ Microbiol 1977, 34:689-694

75. Kubota K, Onoda T, Kamijo H, Yoshinag F, Okumura S: Microbial production of L-arginine. 1. Production of L-arginine by mutants of glutamic acid-producing bacteria. J Gen Appl Microbiol 1973, 19:339-352.

76. Xu H, Dou WF, Xu HY, Zhang XM, Rao ZM, Shi ZP, Xu ZH: A two-stage oxygen supply strategy for enhanced L-arginine production by Corynebacterium crenatum based on metabolic fluxes analysis. Biochem Eng J 2009, 43:41-51.

77. Xu MJ, Rao ZM, Xu H, Lan CY, Dou WF, Zhang XM, Xu HY, Jin JA, Xu ZH: Enhanced production of L-arginine by expression of Vitreoscilla hemoglobin using a novel expression system in Corynebacterium crenatum. Appl Biochem Biotechnol 2011, 163:707-719.

78. Xu MJ, Rao ZM, Yang J, Xia HF, Dou WF, Jin J, Xu ZH: Heterologous and homologous expression of the arginine biosynthetic $\arg \mathrm{C} \sim \mathrm{H}$ cluster from Corynebacterium crenatum for improvement of L-arginine production. J Ind Microbiol Biotechnol 2012, 39:495-502.

79. Choi DK, Ryu WS, Choi CY, Park YH: Production of L-ornithine by arginine auxotrophic mutants of Brevibacterium ketoglutamicum in dual substrate-limited continuous culture. J Ferment Bioeng 1996, 81:216-219.

80. Hwang JH, Hwang $\mathrm{GH}$, Cho JY: Effect of increased glutamate availability on L-ornithine production in Corynebacterium glutamicum. J Microbiol Biotechnol 2008, 18:704-710. 
81. Schneider J, Niermann K, Wendisch VF: Production of the amino acids L-glutamate, L-lysine, L-ornithine and L-arginine from arabinose by recombinant Corynebacterium glutamicum. J Biotechnol 2011, 154:191-198.

82. Lu DM, Liu JZ, Mao ZW: Engineering of Corynebacterium glutamicum to enhance L-ornithine production by gene knockout and comparative proteomic analysis. Chin J Chem Eng 2012, 20:731-739.

83. Hwang GH, Cho JY: Implication of gluconate kinase activity in L-ornithine biosynthesis in Corynebacterium glutamicum. J Ind Microbiol Biotechnol 2012, 39:1869-1874.

84. Jiang LY, Zhang YY, Li Z, Liu JZ: Metabolic engineering of Corynebacterium glutamicum for increasing the production of L-ornithine by increasing NADPH availability. J Ind Microbiol Biotechnol 2013, 40:1143-1151.

85. Jiang LY, Chen SG, Zhang YY, Liu JZ: Metabolic evolution of Corynebacterium glutamicum for increased production of L-ornithine. BMC Biotechnol 2013, 13:47.

86. Kim SY, Lee J, Lee SY: Metabolic engineering of Corynebacterium glutamicum for the production of L-ornithine. Biotechnol Bioeng. in press.

87. Meiswinkel T, Rittmann D, Lindner SN, Wendisch VF: Crude glycerol-based production of amino acids and putrescine by Corynebacterium glutamicum. Bioresour Technol 2013, 145:254-258.

88. Aboulmagd E, Voss I, Oppermann-Sanio FB, Steinbuchel A: Heterologous expression of cyanophycin synthetase and cyanophycin synthesis in the industrial relevant bacteria Corynebacterium glutamicum and Ralstonia eutropha and in Pseudomonas putida. Biomacromolecules 2001, 2:1338-1342.

89. Frey KM, Oppermann-Sanio FB, Schmidt H, Steinbuchel A: Technical-scale production of cyanophycin with recombinant strains of Escherichia coli. Appl Environ Microbiol 2002, 68:3377-3384.

90. Voss I, Diniz SC, Aboulmagd E, Steinbuchel A: Identification of the Anabaena sp strain PCC7120 cyanophycin synthetase as suitable enzyme for production of cyanophycin in gram-negative bacteria like Pseudomonas putida and Ralstonia eutropha. Biomacromolecules 2004, 5:1588-1595.

91. Elbahloul $Y$, Krehenbrink M, Reichelt R, Steinbuchel A: Physiological conditions conducive to high cyanophycin content in biomass of Acinetobacter calcoaceticus strain ADP1. Appl Environ Microbiol 2005 71:858-866

92. Voss I, Steinbuchel A: Application of a KDPG-aldolase gene-dependent addiction system for enhanced production of cyanophycin in Ralstonia eutropha strain H16. Metab Eng 2006, 8:66-78.

93. Kroll J, Klinter S, Steinbuchel A: A novel plasmid addiction system for large-scale production of cyanophycin in Escherichia coli using mineral salts medium. Appl Microbiol Biotechnol 2011, 89:593-604.

94. Lin KC, Elbahloul Y, Steinbuchel A: Physiological conditions conducive to high cell density and high cyanophycin content in Ralstonia eutropha strain $\mathrm{H} 16$ possessing a KDPG aldolase gene-dependent addiction system. Appl Microbiol Biotechnol 2012, 93:1885-1894.

95. Kind S, Jeong WK, Schroder H, Zelder O, Wittmann C: Identification and elimination of the competing $\mathrm{N}$-acetyldiaminopentane pathway for improved production of diaminopentane by Corynebacterium glutamicum. Appl Environ Microbiol 2010, 76:5175-5180.

96. Kroll J, Klinter S, Schneider C, Voss I, Steinbuchel A: Plasmid addiction systems: perspectives and applications in biotechnology. Microb Biotechnol 2010, 3:634-657.

97. Borzi A: Malpighia. In Le comunicazioni intracellulari delle Nostochinee, Volume 1; 1886:28-74

98. Schwamborn M: Chemical synthesis of polyaspartates: a biodegradable alternative to currently used polycarboxylate homo- and copolymers. Polym Degrad Stab 1998, 59:39-45.

99. Zotz RJ, Schenk S, Kuhn A, Schlunken S, Krone V, Bruns W, Genth S, Schuler G: Safety and efficacy of LK565 - a new polymer ultrasound contrast agent. Z Kardiol 2001, 90:419-426.
100. Lutte S, Pohlmann A, Zaychikov E, Schwartz E, Becher JR, Heumann H, Friedrich B: Autotrophic production of stable-isotope-labeled arginine in Ralstonia eutropha Strain H16. Appl Environ Microbiol 2012, 78:7884-7890.

101. Elbahloul Y, Steinbuchel A: Engineering the genotype of Acinetobacter sp strain ADP1 to enhance biosynthesis of cyanophycin. Appl Environ Microbiol 2006, 72:1410-1419.

102. Kroll J, Steinle A, Reichelt R, Ewering C, Steinbuchel A: Establishment of a novel anabolism-based addiction system with an artificially introduced mevalonate pathway: complete stabilization of plasmids as universal application in white biotechnology. Metab Eng 2009, 11:168-177.

\section{doi:10.1186/s12934-014-0166-4}

Cite this article as: Shin and Lee: Metabolic engineering of microorganisms for the production of L-arginine and its derivatives. Microbial Cell Factories 2014 13:166.

\section{Submit your next manuscript to BioMed Central and take full advantage of:}

- Convenient online submission

- Thorough peer review

- No space constraints or color figure charges

- Immediate publication on acceptance

- Inclusion in PubMed, CAS, Scopus and Google Scholar

- Research which is freely available for redistribution

Submit your manuscript at www.biomedcentral.com/submit
C BioMed Central 